Trinity University

Digital Commons @ Trinity

Chemistry Faculty Research

Chemistry Department

2007

\title{
Air and Water Free Solid-Phase Synthesis of Thiol Stabilized Au Nanoparticles with Anchored, Recyclable Dendrimer Templates
}

John D. Gilbertson

Trinity University

G. Vijayaraghavan

K.J. Stevenson

Bert D. Chandler

TrinityUniversity, bchandle@trinity.edu

Follow this and additional works at: https://digitalcommons.trinity.edu/chem_faculty

Part of the Chemistry Commons

\section{Repository Citation}

Gilbertson, J. D., Vijayaraghavan, G., Stevenson, K. J., \& Chandler, B. D. (2007). Air and water free solid-phase synthesis of thiol stabilized au nanoparticles with anchored, recyclable dendrimer templates. Langmuir, 23(22), 11239-11245.

This Article is brought to you for free and open access by the Chemistry Department at Digital Commons @ Trinity. It has been accepted for inclusion in Chemistry Faculty Research by an authorized administrator of Digital Commons @ Trinity. For more information, please contact jcostanz@trinity.edu. 


\title{
Air and Water Free Solid-Phase Synthesis of Thiol Stabilized Au Nanoparticles with Anchored, Recyclable Dendrimer Templates
}

\author{
John D. Gilbertson, ${ }^{\dagger}$ Ganesh Vijayaraghavan,${ }^{\ddagger}$ Keith J. Stevenson, ${ }^{\ddagger}$ and Bert D. Chandler* ${ }^{\dagger}$ \\ Department of Chemistry, Trinity University, San Antonio, Texas 78212-7200, and Department of \\ Chemistry, University of Texas at Austin, 1 University Station A5300, Austin, Texas 78712-0165
}

Received May 10, 2007. In Final Form: August 6, 2007

\begin{abstract}
Solid-phase synthetic templates for Au nanoparticles were developed using Merrifield resins and polyamidoamine (PAMAM) dendrimers. This synthetic scheme affords the opportunity to prepare metal nanoparticles in the absence of air and water, and it does not necessitate phase transfer agents that can be difficult to remove in subsequent steps. Amine-terminated generation 5 PAMAM $\left(\mathrm{G}_{5} \mathrm{NH}_{2}\right)$ dendrimers were grafted to anhydride functionalized polystyrene

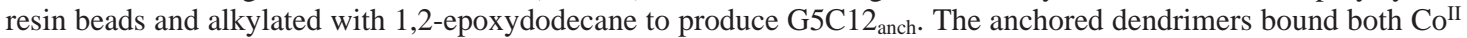
and $\mathrm{Au}^{\mathrm{III}}$ salts from toluene solutions at ratios comparable to those of solution phase alkyl-terminated PAMAM dendrimers. The encapsulated $\mathrm{Au}^{\mathrm{III}}$ salts could be reduced with $\mathrm{NaBH}_{4}$ to produce anchored dendrimer encapsulated nanoparticles (DENs). Treatment of the anchored DENs with decanethiol in toluene extracted the Au nanoparticles from the dendrimers as monolayer protected clusters (MPCs). After a brief $\mathrm{NaCN}$ etch, the anchored dendrimers were readily recycled and a subsequent synthesis of decanethiol Au MPCs was performed with comparable MPC yield and particle size distribution.
\end{abstract}

\section{Introduction}

Metal nanoparticles (NPs) are utilized in a wide variety of disciplines and can be employed as homogeneous or heterogeneous catalysts ${ }^{1}$ as well as biological and molecular sensors. ${ }^{2} \mathrm{~A}$ variety of NP synthetic strategies can be employed, but the most widely used methods utilize a simple metal salt, a reducing agent, and a colloid stabilizer. For example, the Schiffrin and Brust ${ }^{3}$ method involves a biphasic water-organic solvent system where the reduction of a metal salt (e.g., $\mathrm{HAuCl}_{4}$ or $\mathrm{Na}_{2} \mathrm{PdCl}_{4}$ ) is performed in the presence of a colloid stabilizer (typically an alkyl thiol or (4-dimethylamino)pyridine) and a phase transfer reagent such as $\left[\mathrm{N}\left(\mathrm{C}_{8} \mathrm{H}_{17}\right)_{4}\right] \mathrm{Br}$. When $\mathrm{NaBH}_{4}$ is added this suspension, the alkyl thiol serves to arrest nanoparticle growth and carry the reduced metal particle into the organic solvent. Careful control over reagent concentrations allows for substantial control over particle sizes and dispersity.

Polymers such as polyvinylpyrolidine (PVP) and poly(ethylene glycol) can be employed as colloid stabilizers in similar preparative schemes. ${ }^{2}$ Starburst polyamidoamine (PAMAM) dendrimers are a specific class of nearly monodisperse, hyperbranched polymers that have been used to template nearly monodisperse nanoparticles. PAMAM dendrimers, which have open interiors and porous peripheries, serve as both particle templates and stabilizers and can be used in preparing a wide variety of mono- and bimetallic metal NPs. ${ }^{4,5}$ In this synthetic scheme, metal precursors are first bound to the interior amine groups of the PAMAM dendrimer; addition of a reducing agent

* To whom correspondence should be addressed. Telephone: (210) 999 7557. Fax: (210) 999-7569. E-mail: Bert.chandler@trinity.edu.

$\dagger$ Trinity University.

$\doteqdot$ University of Texas at Austin. 7872

(1) Astruc, D.; Lu, F.; Aranzaes, J. R. Angew. Chem., Int. Ed. 2005, 44, 7852-

(2) Daniel, M.-C.; Astruc, D. Chem. Rev. 2004, 104, 293-346.

(3) Brust, M.; Walker, M.; Bethell, D.; Schiffrin, D. J.; Whyman, R. J. Chem. Soc., Chem. Commun. 1994, 801-802.

(4) Crooks, R. M.; Zhao, M.; Sun, L.; Chechik, V.; Yeung, L. K. Acc. Chem. Res. 2001, 34, 181-190.

(5) Scott, R. W. J.; Wilson, O. M.; Crooks, R. M. J. Phys. Chem. B 2005, 109 , $692-704$. prepares particles that are essentially trapped within the dendrimer interior. The dendrimer mediated synthesis allows for greatly increased control over particle size and composition relative to traditional colloid preparation methods. For bimetallic particles, well-mixed and core-shell particles on the order of $2 \mathrm{~nm}$ in diameter can be selectively prepared.

Because PAMAM dendrimers can terminate in a wide variety of end groups $\left(-\mathrm{OH},-\mathrm{NH}_{2}\right.$, and alkyl chains), they can be soluble in either polar or nonpolar solvents, making air and water free ${ }^{6-9}$ syntheses tractable. This is especially important for metals that are readily oxidized. ${ }^{10}$ Additionally, $\mathrm{Au}, \mathrm{Pd}$, and $\mathrm{Ag}$ nanoparticles can be extracted from the dendrimer interior using an appropriate thiol or carboxylate to prepare monolayer protected clusters (MPCs) that are similar to nanoparticles prepared by the Schiffrin and Brust method. Thus, nanoparticles can be prepared in aqueous solution and extracted into organic solvents and vice versa $^{5,9,11}$ (see Scheme 1). This two-phase synthesis provides for substantial flexibility in the synthetic methodologies, a rapid means of eliminating byproducts from the metal reduction step, and allows for recycling of the expensive dendrimer template.

The requirement of aqueous solvents either during metal complexation and reduction or during extraction is a substantial drawback to the Brust-type and dendrimer mediated synthetic schemes. In addition, phase transfer agents can be difficult to isolate from reaction products and are therefore problematic contaminants in Brust-type syntheses. ${ }^{12}$ Aqueous solvents are particularly problematic for oxidizable metals, where water or air can cause substantial changes in nanoparticle structure or

(6) Esumi, K.; Hosoya, T.; Suzuki, A.; Torigoe, K. J. Colloid Interface Sci. 2000, 229, 303-306.

(7) Esumi, K.; Nakamura, R.; Suzuki, A.; Torigoe, K. Langmuir 2000, 16 $7842-7846$

(8) Niu, Y.; Crooks, R. M. Chem. Mater. 2003, 15, 3463-3467.

(9) Knecht, M. R.; Garcia-Martinez, J. C.; Crooks, R. M. Langmuir 2005, 21, $11981-11986$

(10) Knecht, M. R.; Garcia-Martinez, J. C.; Crooks, R. M. Chem. Mater. 2006, $18,5039-5044$.

(11) Garcia-Martinez, J. C.; Crooks, R. M. J. Am. Chem. Soc. 2004, 126, $16170-16178$

(12) Waters, C. A.; Mills, A. J.; Johnson, K. A.; Schiffrin, D. J. Chem. Commun. 2003, 540-541. 
Scheme 1. Synthesis and Extraction of Au DENs as MPCs ${ }^{a}$

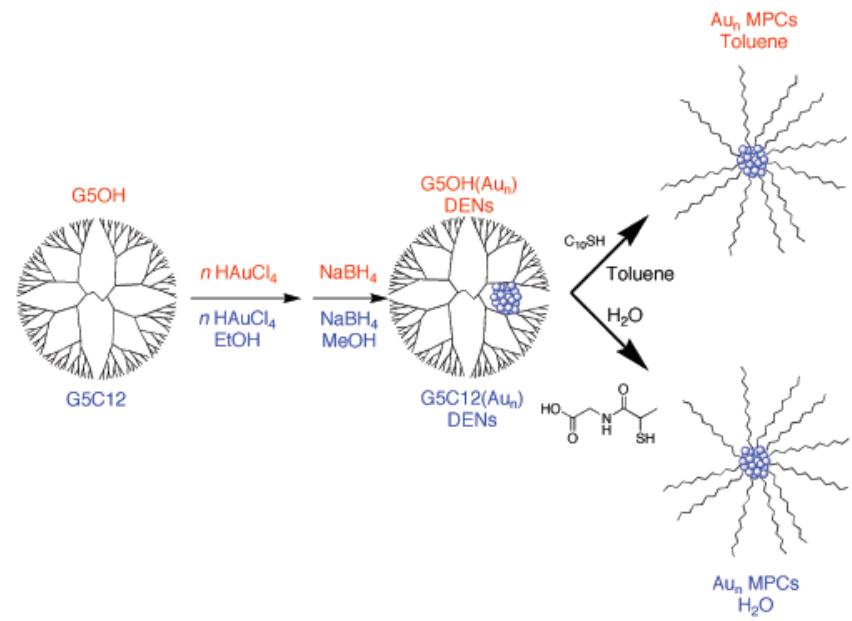

${ }^{a}$ The top (red) reactions are an aqueous synthesis and an organic extraction. The bottom (blue) reactions are an organic synthesis and an aqueous extraction.

morphology. To minimize contact with air or water, it is desirable to perform both nanoparticle synthesis and extraction using nonaqueous solvents and without phase transfer agents. As a result, the development of nonaqueous single-phase syntheses of MPCs has become a topic of recent interest. ${ }^{13}$ These systems typically involve the addition of a metal salt and capping ligand to a nonaqueous solvent followed by the addition of a reducing agent. ${ }^{14-16}$ Reported methodologies typically require very strong reducing agents (e.g., alkyl lithium reagents or superhydride), and the purification routes are often time-consuming. In general, particle sizes and distributions obtained with these methods are not much different from those of the Brust-Schiffrin synthesis. ${ }^{17}$

To address these issues, we developed a synthetic methodology for the solid-phase synthesis of Au nanoparticles using PAMAM dendrimers anchored to commercial Merrifield resins. Since solidphase synthesis was initially introduced by Merrifield, ${ }^{18}$ this protocol has been the standard for preparing peptides and oligonucleotides for a number of years. ${ }^{19}$ The versatility of the solid support has allowed for the synthesis and purification of complex molecules with relative ease. We decided to expand this concept and extend the synthetic utility of Merrifield resins to the synthesis and extraction of NPs. Additionally, we aimed to shorten the time for dendrimer recycling, as traditional dendrimer mediated syntheses require $24 \mathrm{~h}$ of dialysis with multiple solvent changes. Thus, our motivation for this work was to develop air and water free synthetic routes and to facilitate rapid recycling of the dendrimer by eliminating the need for dialysis.

Several research groups have attempted to grow or build low generation dendritic polymers on silica, ${ }^{20-25}$ polystyrene, ${ }^{26-28}$

(13) Cushing, B. L.; Kolesnichenko, V. L.; O’Connor, C. J. Chem. Rev. 2004, 104, 3893-3946.

(14) Shan, J.; Nuopponen, M.; Jiang, H.; Kauppinen, E.; Tenhu, H. Macromolecules 2003, 36, 4526-4533.

(15) Rowe, M. P.; Plass, K. E.; Kim, K.; Kurdak, C.; Zellers, E. T.; Matzger, A. J. Chem. Mater. 2004, 16, 3513-3517.

(16) Yee, C. K.; Jordan, R.; Ulman, A.; White, H.; King, A.; Rafailovich, M.; Sokolov, J. Langmuir 1999, 15, 3486-3491.

(17) Jana, N. R.; Peng, X. J. Am. Chem. Soc. 2003, 125, 14280-14281.

(18) Merrifield, R. B. J. Am. Chem. Soc. 1963, 85, 2149-2154.

(19) Seneci, P. Solid Phase Synthesis and Combinatorial Technologies; John Wiley and Sons: New York, 2000.

(20) Reynhardt, J. P. K.; Yang, Y.; Sayari, A.; Alper, H. Chem. Mater. 2004, 16, 4095-4102.

(21) Reynhardt, J. P. K.; Yang, Y.; Sayari, A.; Alper, H. Adv. Funct. Mater. 2005, 15, 1641-1646.

(22) Reynhardt, J. P. K.; Yang, Y.; Sayari, A.; Alper, H. Adv. Synth. Catal. 2005, 347, 1379-1388. and various resins ${ }^{29,30}$ for the purpose of immobilizing catalysts onto solid supports. ${ }^{31-33}$ One particular study investigated Pd NP catalysts templated on hyperbranched polymers constructed on mesoporous silica. ${ }^{34}$ From the perspective of nanoparticle synthesis, these approaches have substantial drawbacks. The support superstructure often limits the size of dendrimer available (generation 4 or higher dendrimers are preferable for nanoparticle synthesis). Additionally, the materials are extremely timeconsuming to prepare, and it is difficult to ensure that the dendritic materials prepared on the supports are comparable to those in solution.

We reasoned that if it were possible to attach (instead of synthesize) the NP template/stabilizer (dendrimer) to a solid support (resin bead), then it would be possible to carry out the synthesis and extraction of NPs entirely in nonaqueous solvents with relative ease. Our long-term goals are to develop dendrimer mediated synthetic routes to bimetallic Au based nanoparticles and catalysts, particularly for oxidizible first row transition metals. Since there are no appropriate air and water free synthetic routes to Au MPCs, we initially embarked on a proof of concept study to show that the synthesis of monometallic Au MPCs is possible using anchored dendrimers. The details of that study are reported here.

\section{Experimental Section}

Materials and Reagents. MP-anhydride resin $(7.4 \mathrm{mmol}$ anhydride/g resin) was purchased from EMD Biosciences and used as received. Amine terminated generation 5 polyamidoamine (PAMAM) and dodecanol terminated (50\%) generation 5 PAMAM dendrimers were purchased from Dendritech. $\mathrm{HAuCl}_{4}$ (Alfa), $\mathrm{CoCl}_{2}$. $6 \mathrm{H}_{2} \mathrm{O}$ (Aldrich), and decanethiol (Aldrich) were used as received. Reagent grade toluene, methanol, and dimethylformamide (DMF, Fischer) were dried under molecular sieves (Davison, Grade 564, $3 \AA$ ) and otherwise used as received. DMF- $d_{6}$ and $\mathrm{CD}_{3} \mathrm{OD}$ (CIL) were used as received. Water was purified to a resistivity of $17-18$ $\mathrm{M} \Omega \mathrm{cm}$ with a Barnstead Nanopure system.

Characterization. Solution UV - visible absorbance spectra were collected on a Jasco-V-530 spectrometer using quartz cells. Reflectance UV-visible spectra were collected on an Ocean Optics UV-visible-NIR spectrometer equipped with a reflectance probe using the appropriate solid support as the reference. ${ }^{1} \mathrm{H}$ NMR spectra were recorded on a Varian Unity/Inova 400 spectrometer at an operating frequency of $399.96 \mathrm{MHz}$. The ${ }^{1} \mathrm{H}$ chemical shifts were referenced to internal solvent peaks. Transmission electron microscope (TEM) analysis of the nanoparticles was performed with a JEOL 2010F instrument operating at $200 \mathrm{kV}$. Nanoparticles suspended in hexane were drop cast onto a 150 mesh $\mathrm{Cu}$ TEM grid covered with a thin amorphous carbon film. Image analysis was performed with DigitalMicrograph 3.6.1 (Gatan) software. Elemental analyses were performed by Desert Analytics (Tucson, AZ). Attenuated total reflection Fourier transform infrared (ATR-FTIR) spectra were collected on a Thermo-Nicolet Nexus 470 FT-IR instrument using a Smart Golden Gate ATR accessory. Atomic absorption spectroscopy was performed on a Varian Spectra AA

(23) Lu, S.-M.; Alper, H. J. Am. Chem. Soc. 2005, 127, 14776-14784.

(24) Abu-Reziq, R.; Alper, H.; Wang, D.; Post, M. L. J. Am. Chem. Soc. 2006, $128,5279-5282$

(25) Chung, Y.-M.; Rhee, H.-K. Chem. Commun. 2002, 238-239.

(26) Dahan, A.; Portnoy, M. Org. Lett. 2003, 5, 1197-1200.

(27) Dahan, A.; Portnoy, M. Chem. Commun. 2002, 2700-2701.

(28) Sellner, H.; Seebach, D. Angew. Chem., Int. Ed. 1999, 38, 1918-1920.

(29) Lu, S.-M.; Alper, H. J. Am. Chem. Soc. 2003, 125, 13126-13131.

(30) Arya, P.; Panda, G.; Rao, N. V.; Alper, H.; Bourque, S. C.; Manzer, L. E. J. Am. Chem. Soc. 2001, 123, 2889-2890.

(31) Dahan, A.; Portnoy, M. J. Polym. Sci., Part A: Polym. Chem. 2004, 43, 235-262.

(32) McNamara, C. A.; Dixon, M. J.; Bradley, M. Chem. Rev. 2002, 102, 3275-3299.

(33) Song, C. E.; Lee, S. Chem. Rev. 2002, 102, 3495-3524.

(34) Jiang, Y.; Gao, Q. J. Am. Chem. Soc. 2006, 128, 716-717. 
Scheme 2. Anchoring of $\mathrm{G}^{5} \mathrm{NH}_{2}$ to a MP-Anhydride Resin Bead
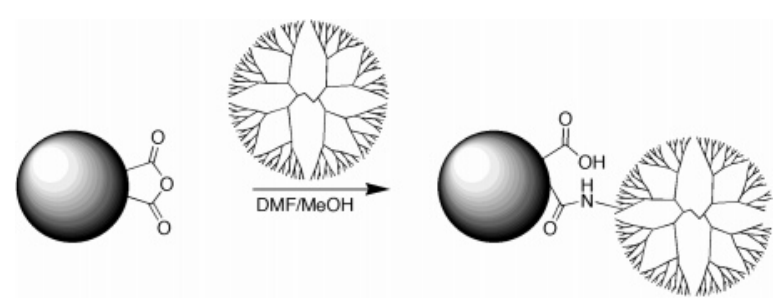

220 FS spectrometer, using sample preparations reported previously..$^{35}$ Briefly, the samples were digested in fresh aqua regia at $60{ }^{\circ} \mathrm{C}$ for $3 \mathrm{~h}$. The solution $\mathrm{pH}$ was adjusted to $4-6$ before the samples were analyzed. MPC samples were purified three times (see the Experimental Section) and subsequently treated in a vacuum oven at $80^{\circ} \mathrm{C}$ overnight (to remove most of the thiol) before being dissolved in aqua regia.

Dendrimer Anchoring and Alkylation. MP-anhydride resin (600 $\mathrm{mg}$; $4.44 \mathrm{mmol}$ anhydride) was swelled in $5 \mathrm{~mL}$ of DMF- $d_{6}$ for 1 $\mathrm{h}$, followed by addition of $10 \mathrm{mg}$ of $\mathrm{G}_{5 \mathrm{NH}_{2}}$ PAMAM dendrimer $(0.35 \mu \mathrm{mol})$ dissolved in $3 \mathrm{~mL}$ of $\mathrm{CD}_{3} \mathrm{OD}$. The vessel was sealed, placed in a shaker at $50 \mathrm{rpm}$, and heated at $45^{\circ} \mathrm{C}$ for $12 \mathrm{~h}$. Inspection of the ${ }^{1} \mathrm{H}$ NMR spectrum of the reaction solution from 2.2 to 3.4 ppm, which showed no resonances due to the dendrimer, indicated that the anchoring reaction was complete. The anchored amine terminated dendrimer is denoted $\mathrm{G} 5 \mathrm{NH} 2_{\text {anch. }}$.

To the above solution, $12.0 \mathrm{mg}(65.1 \mu \mathrm{mol})$ of 1,2-epoxydodecane was added. The solution was shaken at $50 \mathrm{rpm}$ in a sealed vessel at $45^{\circ} \mathrm{C}$ for $48 \mathrm{~h}$. After the reaction, the beads were filtered, rinsed with methanol, and allowed to dry in a vacuum oven at $40{ }^{\circ} \mathrm{C}$ overnight. The alkylated $\mathrm{G} 5 \mathrm{NH} 22_{\text {anch }}$ is denoted $\mathrm{G} 5 \mathrm{C} 12_{\text {anch. }}$.

Preparation of Au Dendrimer Encapsulated Nanoparticles (DENs). G5C12 anch $(0.09 \mu \mathrm{mol} ; 200 \mathrm{mg}$ of $0.45 \mathrm{nmol} \mathrm{G5C12} / \mathrm{mg}$ bead) was stirred in $20 \mathrm{~mL}$ of toluene for $1 \mathrm{~h}$, producing a $4.5 \mu \mathrm{M}$ slurry of G5C12 $2_{\text {anch. }}$ To that mixture, either 1051 or $2813 \mu \mathrm{L}$ of 4.7 $\mathrm{mM} \mathrm{HAuCl}_{4}$ in ethanol was added to the solution to give a $55: 1$ or 147:1 Au/dendrimer molar ratio, respectively. The beads and $\mathrm{HAuCl}_{4}$ were allowed to stir for $1 \mathrm{~h}$ and then were filtered, rinsed with 10 $\mathrm{mL}$ of toluene $(3 \times)$, and redispersed in $20 \mathrm{~mL}$ of fresh toluene. Freshly prepared $50 \mathrm{mM} \mathrm{NaBH}_{4}$ in methanol $(2000 \mu \mathrm{L})$ was then added to the stirring beads, instantly changing their color from yellow to brown.

Extraction and Purification of Au Nanoparticles from the G5C12 $_{\text {anch. The above mixture containing the anchored DENs was }}$ decanted, and $10 \mathrm{~mL}$ of toluene was added to the beads with vigorous stirring (magnetic stir bar with stirrer set on high). Freshly prepared $50 \mathrm{mM} \mathrm{NaBH}_{4}$ in methanol $(1000 \mu \mathrm{L})$ was added, followed instantly by $3000 \mu \mathrm{L}$ of decanethiol in $5 \mathrm{~mL}$ of toluene. The solution turned from colorless to brown after $5 \mathrm{~min}$, but it was allowed to stir for at least $2 \mathrm{~h}$, yielding a brown solution of extracted Au MPCs. The toluene solution containing the MPC product was purified by first concentrating the solution to $1 \mathrm{~mL}$ on a rotary evaporator and then adding $15 \mathrm{~mL}$ of ethanol to precipitate the MPCs. Centrifugation resulted in the separation of the MPCs from excess free $n$-alkanethiol and other impurities. The MPCs were washed and centrifuged twice with ethanol to ensure complete purification. Atomic absorption (AA) spectroscopy showed that the Au was extracted as MPCs in $55 \%$ yield (based on initial $\mathrm{HAuCl}_{4}$ added).

\section{Results and Discussion}

Anchoring of the G5NH2 PAMAM Dendrimer to Polystyrene Resin Bead(s). To develop a synthetic methodology appropriate for the air and water free synthesis of metal thiol stabilized metal nanoparticles, we explored the strategy shown in Scheme 2. Essentially, we drew from existing dendrimer

(35) Lang, H. M.; Iversen, B. L.; Chandler, B. D. J. Am. Chem. Soc. 2003, $125,14832-14836$.

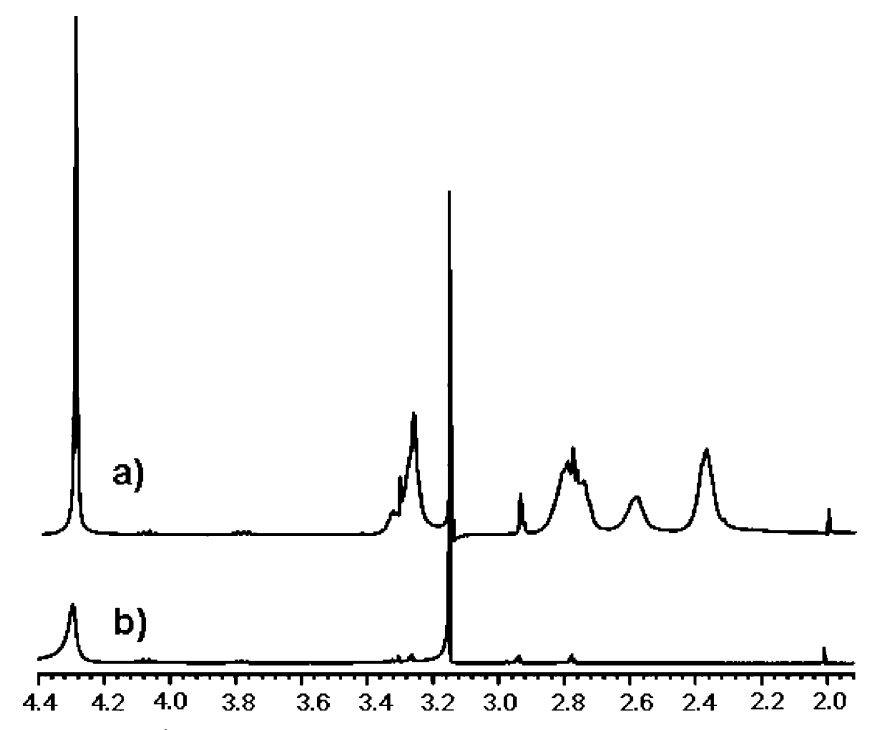

Figure 1. ${ }^{1} \mathrm{H}$ NMR spectra of the reaction mixture $\left(\mathrm{DMF}-d_{6} / \mathrm{CD}_{3}-\right.$ $\mathrm{OD}$ ) of MP-anhydride resin and $\mathrm{G}_{5} \mathrm{NH}_{2}$ (a) before and (b) after reaction. The sharp resonance at $3.16 \mathrm{ppm}$ arises from an impurity in the resin beads.

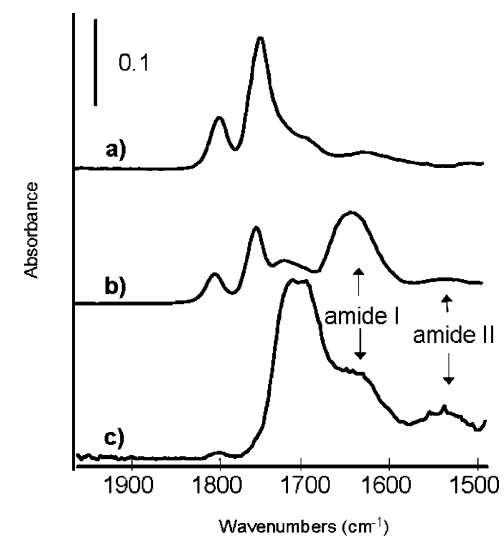

Figure 2. ATR-FTIR spectra of MP-anhydride resin (a) before reaction, (b) after reaction with $\mathrm{G}_{5 \mathrm{NH}}$, and (c) after alkylation with 1,2-epoxydodecane.

immobilization techniques ${ }^{36-38}$ by reacting fifth generation amine terminated PAMAM dendrimers $\left(\mathrm{G} 5 \mathrm{NH}_{2}\right)$ with anhydride functionalized polystyrene Merrifield resin beads. The reaction proceeds quickly and cleanly when 100-fold excess of anhydride to terminal amine groups is used, and the beads are readily filtered after reaction for $12 \mathrm{~h}$. Figure 1 shows the ${ }^{1} \mathrm{H}$ NMR spectrum of the reaction solution (DMF- $d_{6} / \mathrm{CD}_{3} \mathrm{OD}$ ) before and after the reaction. The diagnostic resonances attributed to the methylene protons of $\mathrm{G}_{5 \mathrm{NH}_{2}}$ from 2.2 to 3.4 ppm are present ${ }^{39}$ in the spectrum of the starting material. After the reaction, these resonances have disappeared, indicating that $\mathrm{G}_{5} \mathrm{NH}_{2}$ has been removed from solution.

Figure 2 presents infrared spectra of the amide and carbonyl region of the beads before and after reaction. The peaks at 1822 and $1746 \mathrm{~cm}^{-1}$ in Figure 2a correspond to the anhydride carbonyl bands of the resin beads. ${ }^{40}$ Figure $2 \mathrm{~b}$ shows that the intensity of

(36) Wells, M.; Crooks, R. M. J. Am. Chem. Soc. 1996, 118, 3988-3989. (37) Oh, S.-K.; Kim, Y.-G.; Ye, H.; Crooks, R. M. Langmuir 2003, 19, $10420-$ 10425 .

(38) Tokuhisa, H.; Crooks, R. M. Langmuir 1997, 13, 5608-5612.

(39) Esfand, R.; Tomalia, D. A. In Dendrimers and Other Dendritic Polymers; Frechet, J. M. J., Tomalia, D. A., Eds.; Wiley: West Sussex, U.K., 2001; pp 587-604.

(40) Lin-Vien, D.; Colthup, N. B.; Fateley, W. G.; Grasseli, J. G. Infrared and Raman Characteristic Frequencies of Organic Molecules; Academic Press: San Diego, CA, 1991. 
those bands decreases after the reaction with $\mathrm{G} 5 \mathrm{NH}_{2}$, while new peaks at 1723,1661 , and $1560 \mathrm{~cm}^{-1}$ appear. The peak at 1723 $\mathrm{cm}^{-1}$ is assigned to the carbonyl band of the carboxylic acid produced from reaction with the dendrimer and from methanolysis. The appearance of the amide I and II peaks at 1661 and $1560 \mathrm{~cm}^{-1}$, respectively, arises from both the internal amides of $\mathrm{G}_{5 \mathrm{NH}_{2}}$ as well as the amide bonds formed by reaction with the anhydride bead(s). Thus, the IR data confirm covalent attachment of the dendrimer via amide bond formation and not simple adsorption. ${ }^{38,41}$

The primary goal of developing air and water free synthetic routes to metal nanoparticles necessitated modification of the anchored dendrimers so that they are more compatible with organic solvents. Consequently, the surfaces of the anchored dendrimers were rendered hydrophobic ${ }^{42}$ by reacting the remaining (unreacted) primary amines with 1,2-epoxydodecane (eq 1), producing $\mathrm{G} 5 \mathrm{C} 12_{\text {anch. }}$
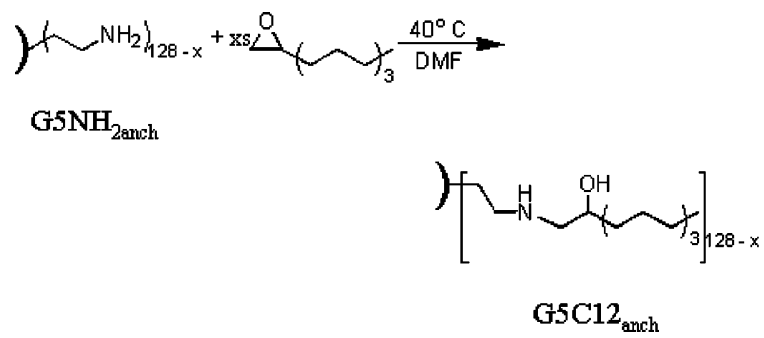

This alkylation was performed to provide additional steric bulk to the dendrimers and ensure that the more polar PAMAM dendrimer superstructure would not collapse upon itself in nonpolar solvents. ${ }^{43}$ This also allowed us to mimic the solution chemistry of G5C12 and prevent linking of the dendrimers through the addition of metal ions..$^{5,44}$

${ }^{1} \mathrm{H}$ NMR of the epoxide solution (see the Supporting Information) indicates that this reaction proceeds to $\sim 50 \%$ completion based on the ratio between added epoxide and primary amine groups. This value is consistent with those of commercially available G5+ PAMAM dendrimers; as the generation increases, it becomes more difficult to completely react the end groups. Additionally, some of the surface amines associated with and near the points of attachment between the dendrimer and the resin bead are expected to be inaccessible to the alkylating agent (either due to steric hindrance or to potential protonation during the anchoring reaction). Figue $2 \mathrm{c}$ also shows that the few remaining bead anhydride groups on the beads are passivated through these treatments. The bands at 1822 and $1746 \mathrm{~cm}^{-1}$ in the carbonyl region are completely replaced with a band at 1723 $\mathrm{cm}^{-1}$, which is assigned to carboxylates formed through methanolysis.

Metal Uptake by the Anchored Dendrimers. In evaluating the anchored hydrophobic dendrimers as nanoparticle templates in organic solvents, it was first necessary to confirm that their capacity for binding metal complexes is not destroyed by the anchoring process. Due to its relatively high extinction coefficient in organic solvents $\left(\sim 10^{3} \mathrm{M}^{-1} \mathrm{~cm}^{-1}\right), \mathrm{CoCl}_{2}$ was chosen to probe

(41) Determination of the dendrimer loading by elemental analysis of the anchored dendrimer beads was undiagnostic due to the residual nitrogen conten in the parent beads $(0.74 \%)$. The theoretical $\% \mathrm{~N}$ of $4.5 \mathrm{E}-04 \mu \mathrm{mol} / \mathrm{mg}$ dendrimer loading was calculated to be $0.48 \%$.

(42) Sayed-Sweet, Y.; Hedstrand, D. M.; Spinder, R.; Tomalia, D. A. J. Mater. Chem. 1997, 7, 1199-1205.

(43) Bosman, A. W.; Janssen, H. M.; Meijer, E. W. Chem. Rev. 1999, 99 , $1655-1688$. 258.

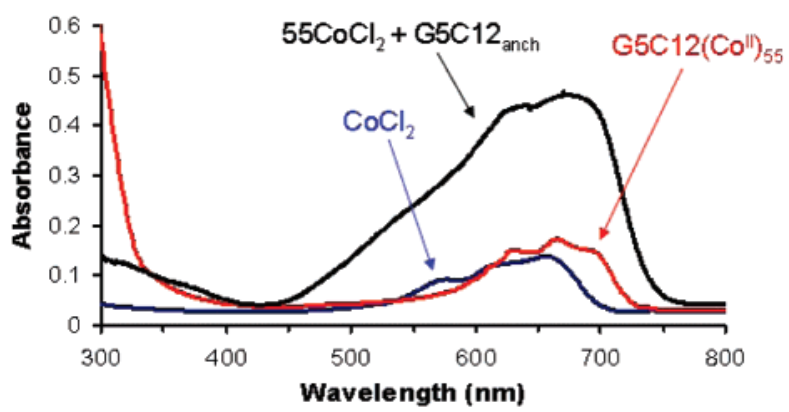

Figure 3. UV-visible spectra of $550 \mu \mathrm{M} \mathrm{CoCl}_{2}$ solutions in ethanol/ toluene mixtures with (blue line) and without (red line) $10 \mu \mathrm{M} \mathrm{G} 5 \mathrm{C} 12$. The black line is a UV-visible reflectance spectrum of a filtered and dried solution of $\mathrm{CoCl}_{2}$ and $\mathrm{G} 5 \mathrm{C} 12_{\text {anch. }}$.

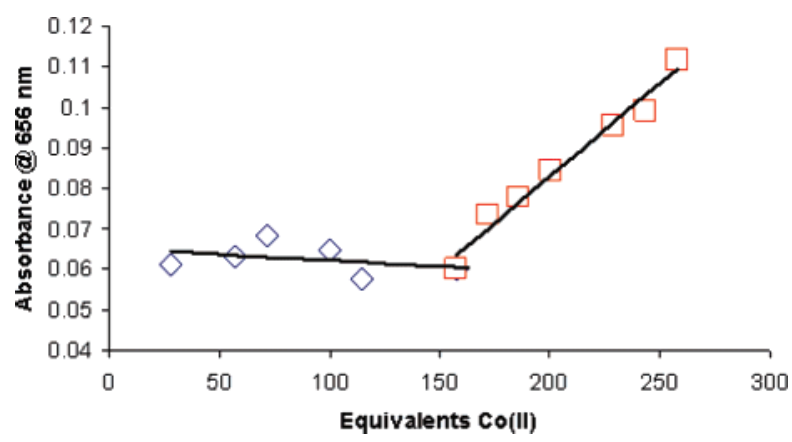

Figure 4. Spectrophotometric titration of $10 \mu \mathrm{M}$ G5C12 2 anch with $\mathrm{CoCl}_{2}$. The blue diamonds correspond to the data before the saturation point. The red squares are from data near or after the saturation point.

metal complexation by G5C12 anch. ${ }^{45}$ Figure 3 shows solution $\mathrm{UV}$ - visible spectra of $\mathrm{Co}^{\mathrm{II}}$ and $\mathrm{Co}^{\mathrm{II}}+\mathrm{G} 5 \mathrm{C} 12$ and a reflectance spectrum of $\mathrm{Co}^{\mathrm{II}}+\mathrm{G} 5 \mathrm{C} 12_{\text {anch. }}$. The $500-700 \mathrm{~nm}$ region in the electronic spectrum exhibits the characteristic multicomponent band associated with the ${ }^{4} \mathrm{~A}_{2} \rightarrow{ }^{4} \mathrm{~T}_{1}$ transition in tetrahedral or pseudotetrahedral $\mathrm{Co}^{\mathrm{II}}$ complexes. ${ }^{46}$ The $\lambda_{\max }$ for this band undergoes a significant red shift $(\sim 50 \mathrm{~nm})$ when $\mathrm{Co}^{\mathrm{II}}$ is added to a toluene solution of $\mathrm{G} 5 \mathrm{C} 12$. This is presumably due to the encapsulation of $\mathrm{Co}^{\mathrm{II}}$ into the dendrimer interior. When a solution of $550 \mu \mathrm{mol} \mathrm{CoCl} 2$ is stirred with $10 \mu \mathrm{mol} \mathrm{G} 5 \mathrm{C} 12_{\text {anch }}$ in toluene, the solution turns colorless, while the beads change from offwhite to blue-green. Control experiments using $\mathrm{CoCl}_{2}$ and unmodified resin beads resulted in no coloration of the beads. The reflectance UV-visible spectrum in Figure 3 shows that the peak corresponding to encapsulated $\mathrm{Co}^{\mathrm{II}}$ is present in the filtered and dried $\mathrm{G} 5 \mathrm{C} 12_{\text {anch }}$, indicating that the $\mathrm{Co}^{\mathrm{II}}$ ions are indeed encapsulated in the $\mathrm{G} 5 \mathrm{C} 12_{\text {anch }}$ in a similar fashion as in a toluene solution of $\mathrm{G} 5 \mathrm{C} 12$.

Figure 4 shows a spectrophotometric titration of $\mathrm{G} 5 \mathrm{C} 12_{\text {anch }}$ with $\mathrm{Co}^{\mathrm{II}}$. This experiment is facilitated by the anchoring because the solution stays colorless as the $\mathrm{Co}^{\mathrm{II}}$ is encapsulated into the G5C12 anch. When more than 150 equiv of $\mathrm{Co}^{\mathrm{II}}$ is added, the solution turns blue and gives a UV-visible spectrum identical to that of $\mathrm{Co}^{\mathrm{II}}$ in solution. This value is slightly greater than the number of tertiary amines present in the dendrimer (126); there

(45) Although $\mathrm{Au}^{\mathrm{III}}$ has a high extinction coefficient in the UV, it is difficult to resolve this band due to the dendrimer. Additionally, $\mathrm{Au}^{\mathrm{III}}$ begins to oxidize $-\mathrm{OH}$ and $-\mathrm{NNH}_{2}$ terminated PAMAM dendrimers over the course of several minutes (see ref 44). The combination of these two factors makes it very difficult to accurately determine $\mathrm{Au}$-dendrimer stoichiometries for the anchored dendrimers. The $\mathrm{Co}^{\mathrm{II}}$ titration is used instead, as it is experimentally straightforward and allows us to directly compare metal uptake by anchored dendrimers to that by solution phase dendrimers.

(46) Lever, A. B. P. Inorganic Electronic Spectroscopy; Elsevier Publishing Company: Amsterdam, 1968; pp 318-325. 


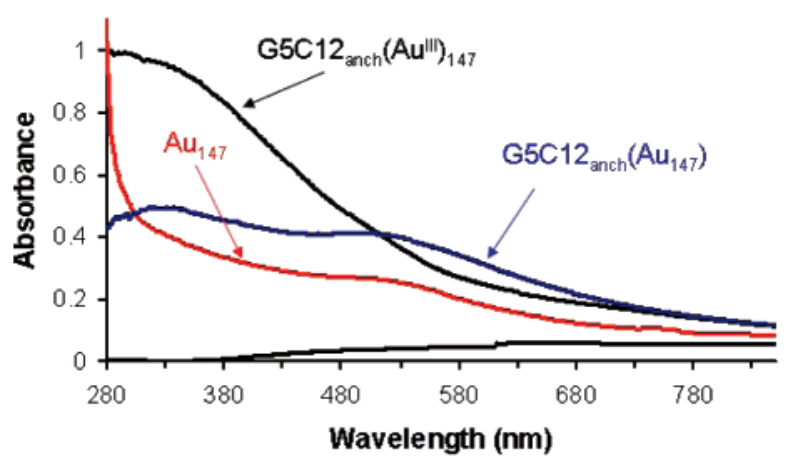

Figure 5. UV-visible reflectance spectra of G5C12( $\left.\mathrm{Au}^{\mathrm{III}}\right)_{147}$ (black) and $2.5 \mu \mathrm{M} \mathrm{G} 5 \mathrm{C} 12\left(\mathrm{Au}_{147}\right) \mathrm{DENs}$ (blue) as well as a solution UVvisible spectrum of $2 \mu \mathrm{M}\left(\mathrm{HSC}_{10}\right) \mathrm{Au}_{147} \mathrm{MPCs}(\mathrm{red})$. The black line with no absorbance is a UV-visible reflectance spectrum of filtered and dried resin beads that were stirred with $\mathrm{HAuCl}_{4}$ (no $\mathrm{Au}^{\mathrm{III}}$ uptake).

are an additional 128 "surface" primary and secondary amines due to the alkylation step. This value is in good agreement with that of the $\mathrm{Co}^{\mathrm{II}}$ encapsulation capacity of $\mathrm{G} 5 \mathrm{C} 12$ in solution, which was determined to be 165 equiv (see the Supporting Information).

Air and Water Free Preparation of Au DENs. The essence of this study was to develop a synthetic procedure suitable for the air and water free preparation of metal nanoparticles. As such, we prepared Au MPCs as a critical proof of concept for the synthetic strategy. The Au DENs were prepared by adding $\mathrm{HAuCl}_{4}$ in ethanol to a toluene slurry of $\mathrm{G} 5 \mathrm{C} 12_{\text {anch }}$ using either a 55:1 or 147:1 Au/dendrimer ratio. The solution turned colorless, and the beads turned pale yellow over a period of $1 \mathrm{~h}$. The reflectance $\mathrm{UV}$-visible spectrum of the filtered and dried $\mathrm{G} 5 \mathrm{C} 12_{\text {anch }}\left(\mathrm{Au}^{\mathrm{III}}\right)_{n}$ is similar to the solution $\mathrm{UV}-$ visible spectrum of $\mathrm{G} 5 \mathrm{C} 12\left(\mathrm{Au}^{\mathrm{III}}\right)_{n}$, indicating that the $\mathrm{Au}$ is encapsulated within the dendrimer (see the Supporting Information). The nomenclature used is consistent with that utilized for Au DENs and MPCs and indicates the metal/dendrimer ratio used in the synthesis rather than the ultimate cluster size.

Addition of $\mathrm{NaBH}_{4}$ to the slurry caused the beads to turn from pale yellow to brown, which is characteristic of Au DENs. ${ }^{4,5}$ As Figure 5 shows, the reflectance UV-visible spectrum of the filtered and dried $\mathrm{G} 5 \mathrm{C} 12_{\text {anch }}\left(\mathrm{Au}_{147}\right)$ shows the monotonic increase in absorbance with decreasing wavelength that is characteristic of Rayleigh scattering by nanoparticles. ${ }^{47}$ An additional small absorption band appears as a shoulder, which is attributable to the surface plasmon band. The reflectance UV-visible spectrum of the filtered and dried $\mathrm{G} 5 \mathrm{C} 12_{\mathrm{anch}}\left(\mathrm{Au}_{55}\right)$ is very similar (see the Supporting Information) and will be discussed below.

To confirm that the anchored dendrimers template nanoparticles as they do in solution, ${ }^{4,5,11}$ two sets of control experiments were performed. First, when stirred with $\mathrm{HAuCl}_{4}$, unmodified resin beads showed no metal uptake over the course of $6 \mathrm{~h}$. In a second comparable control experiment, $\mathrm{GNNH}_{2}$ was anchored to the MP-anhydride resin and alkylated with 1,2 epoxydodecane (see the Supporting Information). When stirred with $\mathrm{Au}^{\mathrm{III}}$ in a comparable stoichiometry to that of G5C12 anch, G0C $12_{\text {anch }}$ bound only a small fraction of the metal. After reduction, the UVvisible reflectance spectrum of the filtered beads contained a very large plasmon band, indicating the presence of large $\mathrm{Au}$ particles (vida infra). No Au MPCs were produced or extracted upon vigorous stirring with decanethiol, which is similarly indicative of the presence of large particles trapped in the

(47) Kreibig, U. V. M. Optical Properties of Metal Clusters; Springer: Berlin, 995. polystyrene (vida infra). The combination of these control experiments demonstrates that the $\mathrm{G} 5 \mathrm{C} 12_{\text {anch }}$ is indeed responsible for the NP templating. TEM images of the anchored DENs prior to extraction were collected, and they are available in the Supporting Information. Unfortunately, the size/thickness of the resin bead support prevents the observation of conclusive TEM evidence for the size of the NPs in the G5C12 anch $\left(\mathrm{Au}_{n}\right)$ samples prior to extraction. In a sense, the bead acts like an undried drop of the casting solvent, surrounding the particles with a variable layer of organic material that makes imaging small nanoparticles, which have relatively low electron densities, difficult. At the same time, large Au agglomerates, which would be far easier to image, were not observed, suggesting that the anchored DENs consist of small nanoparticles.

Extraction of Au MPCs. Beyond the utility of developing solid-phase synthetic procedures for nanoparticles, the conversion of $\mathrm{Au}$ DENs to $\mathrm{Au}$ MPCs affords the opportunity to prepare $\mathrm{Au}$ (and ultimately Au based bimetallic) nanoparticles in the absence of both water and air. The addition of 100-fold molar excess of decanethiol to toluene slurries of freshly reduced $\mathrm{G} 5 \mathrm{C} 12_{\mathrm{anch}^{-}}$ $\left(\mathrm{Au}_{n}\right)$ DENs (where $n=55$ or 147) resulted in the solutions changing from colorless to brown. ${ }^{48}$ The solution UV-visible spectrum of the extracted $\mathrm{Au}_{147}$ MPC solution shown in Figure 5 is comparable to spectra reported by Crooks' group. ${ }^{4,5,11}$ The plasmon band that was present in the reflectance spectrum for the G5C12 anch $\left(\mathrm{Au}_{n}\right)$ DENs is diminished significantly, indicating that the extracted Au NPs are smaller than $3 \mathrm{~nm} .{ }^{49}$ The TEM micrographs and particle size distribution histograms in Figure 6 show an average diameter of $2.5 \pm 0.5 \mathrm{~nm}$, confirming this result. Results with $\mathrm{Au}_{55}$ MPCs are similar $(2.0 \pm 0.7 \mathrm{~nm})$, and a TEM micrograph, particle size distribution histogram, and solution $\mathrm{UV}-$ visible spectrum of the $\mathrm{Au}_{55}$ MPCs can be found in the Supporting Information. AA spectroscopy of the MPC solutions indicates that the overall yield for the synthesis is $55 \%$ (based on the initial amount of $\mathrm{HAuCl}_{4}$ used).

In both cases $\left(\mathrm{Au}_{55}\right.$ and $\left.\mathrm{Au}_{147}\right)$, the extracted particles are slightly larger than those reported by Crooks' group. ${ }^{4,5,11}$ The resin bead prevents conclusive TEM evidence for the size of the NPs in the G5C12 anch $\left(\mathrm{Au}_{n}\right)$ samples (vida supra); however, the $\mathrm{UV}$-visible spectra of $\mathrm{G} 5 \mathrm{C} 12_{\text {anch }}\left(\mathrm{Au}_{n}\right)$ and $\mathrm{G} 5 \mathrm{C} 12\left(\mathrm{Au}_{n}\right)$ are similar, which suggests comparable particle sizes prior to extraction. Further evidence for particle growth during the extraction can be found in the beads themselves, which develop a purple tint during extraction. This suggests that some Au remains on the beads as larger particles; atomic absorption spectroscopy confirmed this conjecture, showing that approximately $18 \%$ of the $\mathrm{Au}$ used in the synthesis remained on the bead. Figure 7 shows the reflectance UV-visible spectrum of the beads before and after extraction. The anchored DENs have only a very weak plasmon band; however, the extracted beads show a larger plasmon band than that present in the anchored DENs. Miyake's group has previously shown that the plasmon band intensity increases with particle size ${ }^{50}$ supporting the conclusion that that larger Au particles are formed and subsequently trapped inside the beads during extraction.

Crooks' group has previously established that thiol extraction (aqueous to organic phase) can have a dramatic effect on the particle size if insufficient thiol is used. ${ }^{11}$ Specifically, during extraction, the nascent MPCs are susceptible to aggregation if

(48) No NP extraction was observed for unalkylated $\mathrm{G} 5 \mathrm{NH} 2_{\text {anch }}$, lending credence to the conclusion that the alkylation step does indeed occur and is important to keep the dendrimer from collapsing on itself in nonpolar media.

(49) Mulvaney, P. Langmuir 1996, 12, 788-800.

(50) Shimizu, T.; Teranishi, T.; Hasegawa, S.; Miyake, M. J. Phys. Chem. B 2003, 107, 2719-2724. 

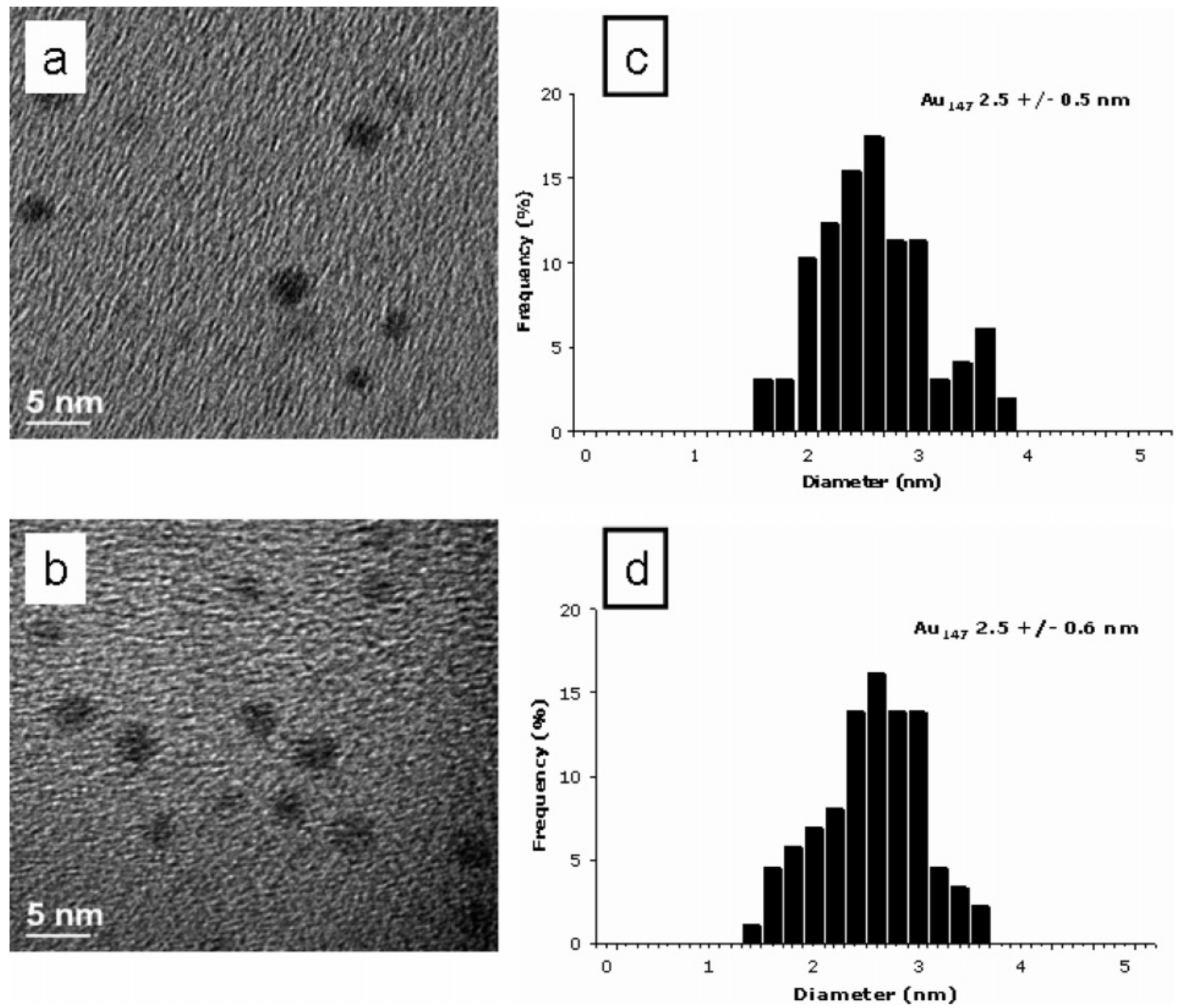

Figure 6. TEM images of successive syntheses and extractions of $\left(\mathrm{C}_{10} \mathrm{SH}\right) \mathrm{Au}_{147} \mathrm{MPCs}$ synthesized from (a) fresh G5C12 anch and (b) recycled G5C12 anch. The corresponding particle size distributions (100 particles) for the (c) fresh and (d) recycled samples are shown to the right.

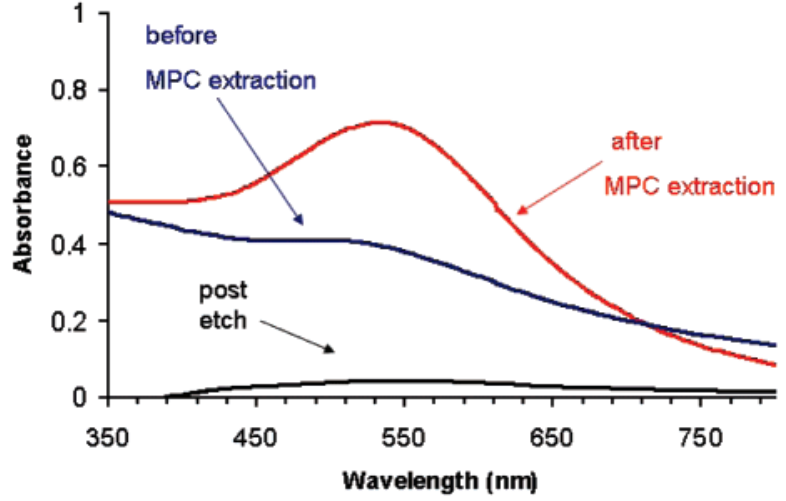

Figure 7. UV-visible reflectance spectra of $\mathrm{G} 5 \mathrm{C} 12_{\text {anch }}$ before (blue) and after (red) MPC extraction. The black line corresponds to G5C12 anch after an aqueous $\mathrm{NaCN}$ etch.

the particles are not fully passivated. It is therefore important to use a thiol/Au mole ratio of at least 100 to drive the $\mathrm{Au}$-thiol binding kinetics and facilitate extraction without agglomeration. In aqueous-organic extractions, the NPs are completely extracted from the dendrimer in approximately $1 \mathrm{~min}$, while NP extraction from $\mathrm{G} 5 \mathrm{C} 12_{\text {anch }}$ takes $5-120 \mathrm{~min}$.

Crooks' group reported that two-phase aqueous-organic extractions are performed by shaking in a separatory funnel by hand, while the single-phase extractions for $\mathrm{G} 5 \mathrm{C} 12_{\text {anch }}$ reported here are performed by adding the thiol directly to the toluene phase under vigorous stirring with a magnetic stir bar. ${ }^{11}$ This gives the aqueous-organic extractions much larger surface contact between the DENs and thiol layers than is possible with the beads, and it may account for the differences in extraction times and particle size distributions. Additionally, extraction in the two-phase method is facilitated by the addition of excess $\mathrm{NaBH}_{4}$ to the aqueous solution immediately before extraction. This ensures that the Au nanoparticle surface is freshly reduced and increases the ionic strength of the aqueous solution, thus "opening up" the dendrimer. In the case of the solid-phase extraction, an excess of $\mathrm{NaBH}_{4}$ in methanol is used as a substitute since solid $\mathrm{NaBH}_{4}$ is not soluble in toluene. This may also account for some particle agglomeration; however, it should be noted that in organic to aqueous extractions ${ }^{9}$ no extra $\mathrm{NaBH}_{4}$ is required. Finally, it also cannot be ruled out that the broader particle size distributions observed for the solid-phase synthesis are a consequence of the nascent MPCs having a difficult time escaping from the dendrimer interior, causing a degree of agglomeration or aggregation within the pores of the beads.

Since these larger particles are formed during extraction, further refinements to this synthetic step may improve the overall dispersity of the MPCs. Although refining the extraction procedure may lead to slightly smaller particle sizes and more narrow distributions, the anchored dendrimers clearly accomplish the goal of this work: they are viable templates for the preparation 


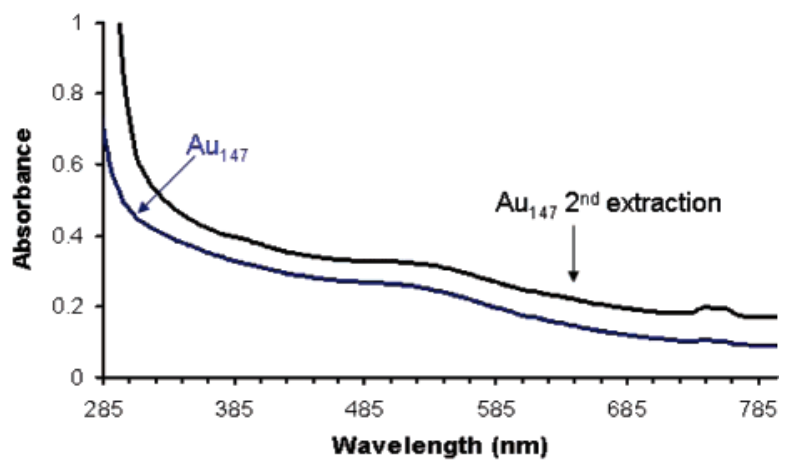

Figure 8. UV-visible spectra of solutions of successive syntheses and extractions of $\sim 2 \mu \mathrm{M}$ ( $\left.\mathrm{HSC}_{10}\right) \mathrm{Au}_{147}$ MPCs before (blue) and after (black) an aqueous $\mathrm{NaCN}$ etch.

of relatively small nanoparticles in the absence of both water and air. Additionally, this new synthetic scheme requires much weaker reducing agents than those of other single-phase nanoparticle preparation methods. ${ }^{10-13}$ Evaluating potential improvements to the scheme is nonetheless useful in evaluating and ultimately refining the synthetic methodology. The bead pore structure appears to play a key role, so employing resins or supports with larger, well-defined, and more accessible pore structures should facilitate thiol access to the NPs and reduce the degree of agglomeration. It may also be possible to improve particle size distributions by using shorter chain alkyl thiols or by employing more vigorous mixing methods (e.g., vortexing). Current work in our lab is directed toward implementing these refinements and extending this templating scheme to additional metal systems.

Recyclability of $\mathbf{G 5 C 1 2}$ anch. In addition to the exclusive utilization of nonaqueous solvents, another advantage of an anchored system is the possibility of rapidly and easily recycling the dendrimer. To recycle the anchored dendrimer, the unextracted Au was first etched using aqueous $\mathrm{NaCN} .{ }^{51,52}$ Reflectance UVvisible spectra of $\mathrm{G} 5 \mathrm{C} 12$ anch before and after etching, shown in Figure 7 , indicate that the $\mathrm{G} 5 \mathrm{C} 12_{\text {anch }}$ is free of residual $\mathrm{Au}$ after the etch.

The G5C12 anch was then used to synthesize a second batch of $\mathrm{Au}_{147}$. Figure 8 shows that the UV-visible spectra of the successive $\mathrm{Au}_{147}$ MPC extractions are essentially identical. TEM

(51) Chen, S. Langmuir 1999, 15, 7551-7557.

(52) Chen, S.; Murray, R. W. Langmuir 1999, 15, 682-689. micrographs and particle size distribution histograms of the two samples are shown in Figure 6. Both samples are nearly identical in both particle size and distribution $(2.5 \pm 0.5$ and $2.5 \pm 0.6$ $\mathrm{nm}$, respectively). The MPC yield from this second synthesis (46\%) was comparable to the yield from the fresh sample, but it was slightly lower.

\section{Conclusions}

We have shown that it is possible to utilize solid-phase synthesis techniques to prepare small $(<3 \mathrm{~nm})$, fairly monodisperse $\mathrm{Au}$ NPs exclusively using organic solvents. The development of this preparative scheme is important because it affords opportunities to develop new synthetic routes to metal nanoparticles in the absence of air, water, and difficult to remove phase transfer agents. As a proof of principle, we prepared Au MPCs, which also allowed us to compare this new synthetic scheme to existing methodologies. This was accomplished by first anchoring fifth generation PAMAM dendrimers to anhydride functionalized polystyrene resin beads. The dendrimers were then alkylated, and their propensity to encapsulate metal ions was demonstrated by $\mathrm{Co}^{\mathrm{II}}$ titrations. Au DENs were then synthesized and extracted as MPCs in the same solvent from which they were prepared (toluene). The measured particle sizes were slightly larger than predicted for $\mathrm{Au}_{147}$ and $\mathrm{Au}_{55} \mathrm{NPs}$; however, the particle sizes and distributions compare favorably with those prepared by Brust-Schiffrin and related methodologies. The key advance here is that the anchored dendrimer method eliminates the need for a biphasic synthesis with water, eliminates the use of difficult to remove phase transfer agents, and requires weaker reducing agents than comparable single-phase nanoparticle syntheses. In addition, the anchored, alkylated dendrimers were also shown to be recyclable in the synthesis of Au NPs of nearly identical size and distribution as those of the first batch.

Acknowledgment. The authors gratefully acknowledge the Robert A. Welch Foundation (Grant Nos. W-1552 and F-1529) and the U.S. National Science Foundation (Grant No. CHE0449549) for financial support of our work.

Supporting Information Available: Experimental details for the ${ }^{1} \mathrm{H}$ NMR determination of the alkylation reaction of $\mathrm{G}^{2} \mathrm{NH}_{2}, \mathrm{Co}^{\mathrm{II}}$ titration of $\mathrm{G} 5 \mathrm{C} 12$ in toluene, $\mathrm{G} 0 \mathrm{NH} 2_{\text {anch }}$ synthesis and reactions, as well as representative UV-visible spectra, TEM images, and particle size distribution for $\mathrm{Au}_{55}$. This material is available free of charge via the Internet at http://pubs.acs.org.

LA7013573 


\section{Supporting Information}

\section{Solid Phase Synthesis of Soluble Nanoparticles with Anchored,}

\section{Recyclable Dendrimer Templates}

John D. Gilbertson, ${ }^{\text {A }}$ Ganesh Vijayaraghavan, ${ }^{B}$ Keith J. Stevenson, ${ }^{B}$ and Bert D. Chandler ${ }^{*}, \mathrm{~A}$

${ }^{A}$ Department of Chemistry, Trinity University, San Antonio, TX 78212-7200, and

${ }^{\mathrm{B}}$ Department of Chemistry, University of Texas at Austin, 1 University Station A5300,

Austin, Texas 78712-0165

*Bert.chandler@trinity.edu

\section{Table of Contents}

\section{Experimental procedures}

Figure S1. Determination of the reaction yield of 1,2-epoxydodecane with

$$
\mathrm{G}_{5} \mathrm{NH}_{2 \text { anch }} \text { by }{ }^{1} \mathrm{H} \mathrm{NMR} \text {. }
$$

p. S4

Figure S2. UV-Vis titration plot of Co ${ }^{\mathrm{II}}$ uptake by G5C12.

p. S4

Figure S3. UV-visible spectra of $\mathrm{HAuCl}_{4}, \mathrm{HAuCl}_{4}+\mathrm{G} 5 \mathrm{C} 12_{\text {anch }}$, and $\mathrm{G} 5 \mathrm{C} 12\left(\mathrm{Au}^{\mathrm{III}}\right)_{55}$

Figure S4. Selected UV-Vis spectra during $\mathrm{Au}_{55} \mathrm{MPC}$ synthesis and extraction.

p. S5

Figure S5. TEM image of $\left(\mathrm{C}_{10} \mathrm{SH}\right) \mathrm{Au}_{55}$ MPCs synthesized from $\mathrm{G} 5 \mathrm{C} 12_{\text {anch }}$

p. S6

Figure S6. TEM images of $\mathrm{G} 5 \mathrm{C} 12_{\text {anch }}\left(\mathrm{Au}_{147}\right)$ pre extraction

p. S6 


\section{Determination of the reaction yield of 1,2-epoxydodecane with G5NH $\mathrm{Nanch}_{\mathbf{2}}$}

To a freshly prepared solution $\left(5 \mathrm{~mL} \mathrm{DMF}-d_{6}+3 \mathrm{~mL} \mathrm{CD}_{3} \mathrm{OD}\right)$ of $2.0 \mathrm{~g}(1.2 \mu \mathrm{mol})$

G5 $\mathrm{NH}_{2 \mathrm{anch}}, 75 \mu \mathrm{mol}$ toluene was also added as an internal standard and allowed to shake at $50 \mathrm{rpm}$ in a sealed vessel at $45^{\circ} \mathrm{C}$ for 2 hours (to account for any loss due to swelling of the beads). After two hours, $30.0 \mathrm{mg}$ (163 $\mu \mathrm{mol})$ 1,2-epoxydodecane was added and an aliquot was immediately analyzed by ${ }^{1} \mathrm{H}$ NMR. The solution was then shaken at 50 rpm in a sealed vessel at $45^{\circ} \mathrm{C}$ for 48 hours and analyzed by ${ }^{1} \mathrm{H}$ NMR every 24 hours. The resonances at $2.6 \mathrm{ppm}$ (1,2-epoxydodecane) and $7.2 \mathrm{ppm}$ (toluene) were integrated and compared to determine $~ 50 \%$ coverage of $\mathrm{G}_{5 \mathrm{NH}_{2} \text { anch }}$ by 1,2-epoxydodecane to produce $\mathrm{G} 5 \mathrm{C} 12_{\text {anch }}$ after 48 hours.

UV-Vis titration plot of $\mathrm{Co}^{\mathrm{II}}$ complexation by G5C12 in solution. In a quartz $\mathrm{UV}$-Vis cuvette, $5 \mathrm{~mL}$ of a $2.2 \mu \mathrm{M}$ solution of G5C12 in toluene was stirred. To that solution, $17 \mu \mathrm{L}$ of an $8.4 \mathrm{mM}$ solution of $\mathrm{CoCl}_{2} \cdot 6 \mathrm{H}_{2} \mathrm{O}$ in EtOH was added every 5 minutes with stirring. A UV-Vis spectrum of the solution was collected after each aliquot (up to 400 equivalents $\mathrm{Co}^{\mathrm{II}}$ ) was added.

G0NH 2 anchoring and alkylation. $500 \mathrm{mg} \mathrm{Mp}$-anhydride resin $(3.70 \mathrm{mmol}$ anhydride) was swelled in $5 \mathrm{~mL}$ DMF for one hour, followed by addition of $6 \mathrm{mg} \mathrm{G0NH} 2$ PAMAM dendrimer $(0.122 \mu \mathrm{mol})$ dissolved in $3 \mathrm{~mL} \mathrm{CH}_{3} \mathrm{OH}$. The vessel was sealed, placed in a shaker at $50 \mathrm{rpm}$, and heated at $45{ }^{\circ} \mathrm{C}$ for 12 hours. The anchored amine terminated dendrimer is denoted $\mathrm{G} 0 \mathrm{NH} 22_{\text {anch. }}$

To the above solution $12.0 \mathrm{mg}(65.1 \mu \mathrm{mol})$ 1,2-epoxydodecane was added. The solution was shaken at $50 \mathrm{rpm}$ in a sealed vessel at $45{ }^{\circ} \mathrm{C}$ for 48 hours. After reaction, the 
beads were filtered, rinsed with $\mathrm{MeOH}$, and allowed to dry in a vacuum oven at $40{ }^{\circ} \mathrm{C}$ overnight. The alkylated $\mathrm{G} 0 \mathrm{NH} 2_{\text {anch }}$ is denoted $\mathrm{G} 0 \mathrm{C} 12_{\text {anch. }}$.

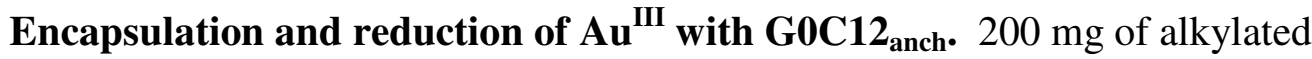
anchored dendrimer beads (G0C12 $\left.{ }_{\text {anch }}\right)$ containing an average dendrimer loading of 4.65 $\mu \mathrm{mol}$ were stirred in $20 \mathrm{~mL}$ toluene for one hour. To that mixture, $3 \mathrm{mg}$ of $\mathrm{HAuCl}_{4}$ in 1 $\mathrm{mL}$ of EtOH was added to the solution to simulate a 55:1 Au:dendrimer molar ratio, respectively. This simulated ratio is based on the \# of primary amines present (which is the same as in the $\mathrm{G} 5 \mathrm{C} 12_{\text {anch }}$ ) allowing comparison of the respective templating ability of the two different generation of dendrimers. The beads and $\mathrm{HAuCl}_{4}$ were allowed to stir for one hour and then were filtered, rinsed with $10 \mathrm{~mL}(3 \mathrm{x})$ toluene, and redispersed in 20 $\mathrm{mL}$ fresh toluene. $2000 \mu \mathrm{L}$ of a freshly prepared $50 \mathrm{mM} \mathrm{NaBH}_{4}$ in $\mathrm{MeOH}$ was then added to the stirring beads, instantly changing their color from yellow to purple.

Extraction of Au nanoparticles from the $\mathbf{G 0 C 1 2}_{\text {anch. The above mixture was }}$ decanted and $10 \mathrm{~mL}$ of toluene containing $3000 \mu \mathrm{L}$ decanethiol was added to the beads with vigorous stirring. The solution remained colorless, and the beads remained purple, after stirring for 24 hours. No extraction was observed. 


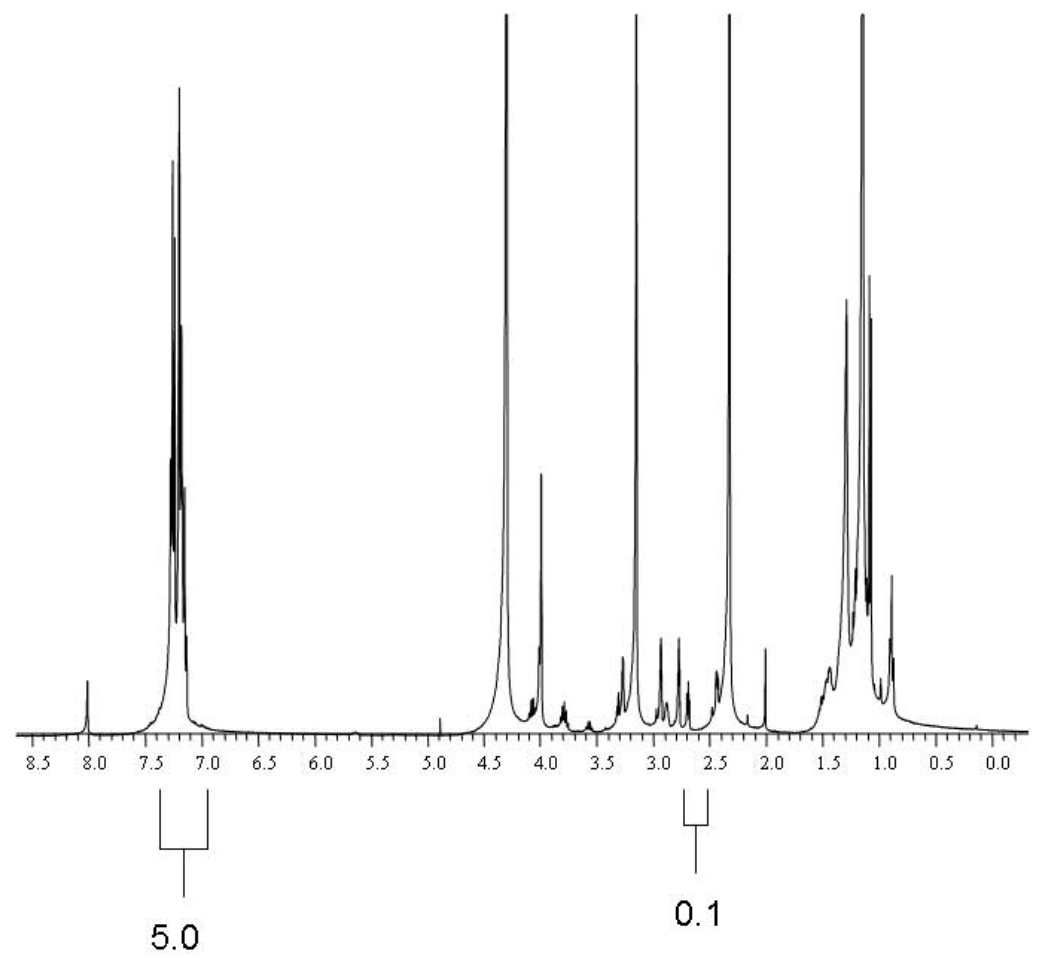

Figure S1. ${ }^{1} \mathrm{H}$ NMR spectrum of the reaction mixture between $\mathrm{G}_{5} \mathrm{NH}_{2}$ anch and 1,2epoxydodecane after 48 hours. The resonance at $7.2 \mathrm{ppm}$ corresponds to an internal standard of $75 \mu \mathrm{mol}$ toluene. The resonance at $2.6 \mathrm{ppm}$ is attributed to one proton on the unreacted 1,2-epoxydodecane.

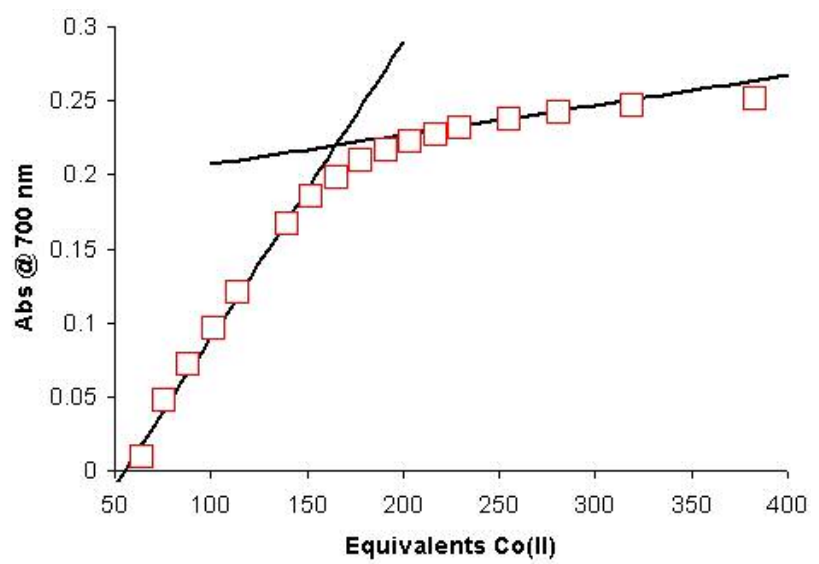

Figure S2. Titration plot of Co ${ }^{\text {II }}$ uptake by $2.2 \mu \mathrm{M}$ G5C12 with in solution. The intersection point corresponds to $\sim 165$ equivalents of $\mathrm{Co}^{\text {II }}$ per dendrimer. 


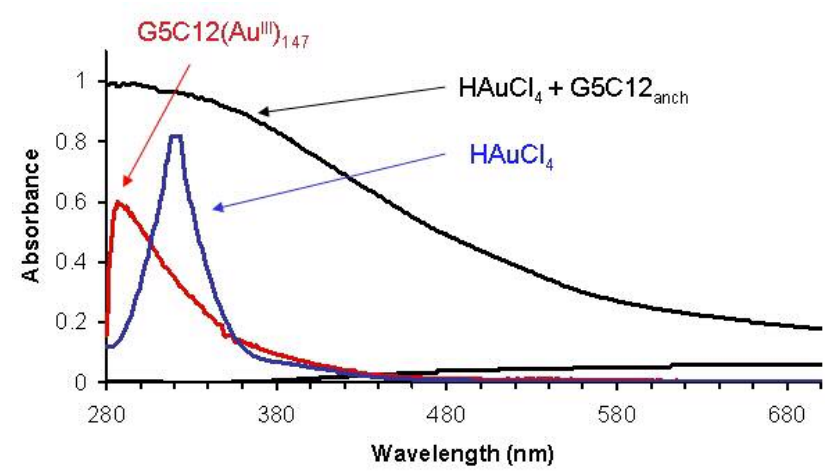

Figure S3. UV-visible spectra of solutions of $200 \mu \mathrm{M} \mathrm{HAuCl}_{4}$ (blue line) and $\mathrm{G} 5 \mathrm{C} 12\left(\mathrm{Au}^{\mathrm{III}}\right)_{147}$ (red line) in EtOH/toluene. The black line is a UV-visible reflectance spectrum of filtered and dried $\mathrm{HAuCl}_{4}$ and $\mathrm{G} 5 \mathrm{C} 12_{\text {anch. }}$.

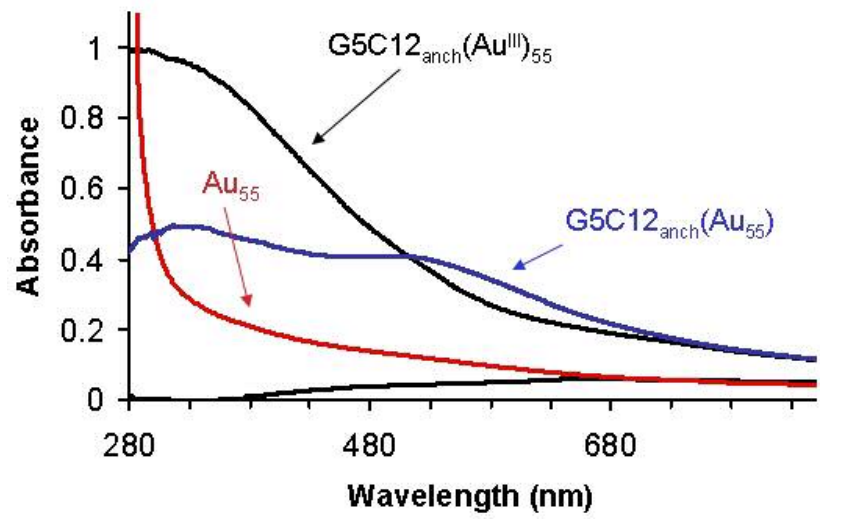

Figure S4. UV-Vis reflectance spectra of G5C12 anch $\left(\mathrm{Au}^{\mathrm{III}}\right)_{55}$ (black) and G5C12 anch $\left(\mathrm{Au}_{55}\right)$ DENs (blue), as well as a solution UV-Vis spectrum of $\left(\mathrm{C}_{10} \mathrm{SH}\right) \mathrm{Au}_{55}$ MPCs (red). The black line with no absorbance is a UV-Vis reflectance spectrum of filtered and dried resin beads that were stirred with $\mathrm{HAuCl}_{4}$ (no $\mathrm{Au}^{\mathrm{III}}$ uptake). 

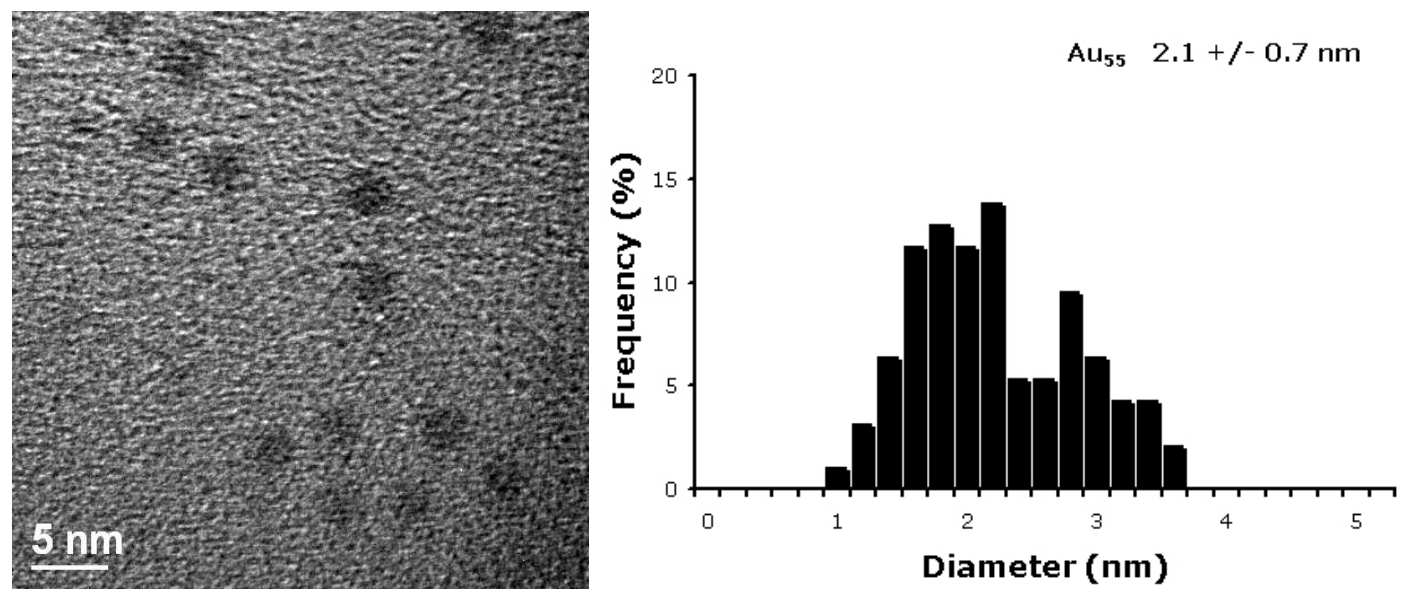

Figure S5. TEM image of $\left(\mathrm{C}_{10} \mathrm{SH}\right) \mathrm{Au}_{55}$ MPCs synthesized from $\mathrm{G} 5 \mathrm{C} 12_{\text {anch. The }}$ corresponding particle size distribution (100 particles) is also shown. Note: the larger and somewhat bimodal particle size distribution may indicate that the anchored dendrimers are less effective at templating smaller particles, or that the extraction is less effective for the smaller metal:dendrimer ratio.
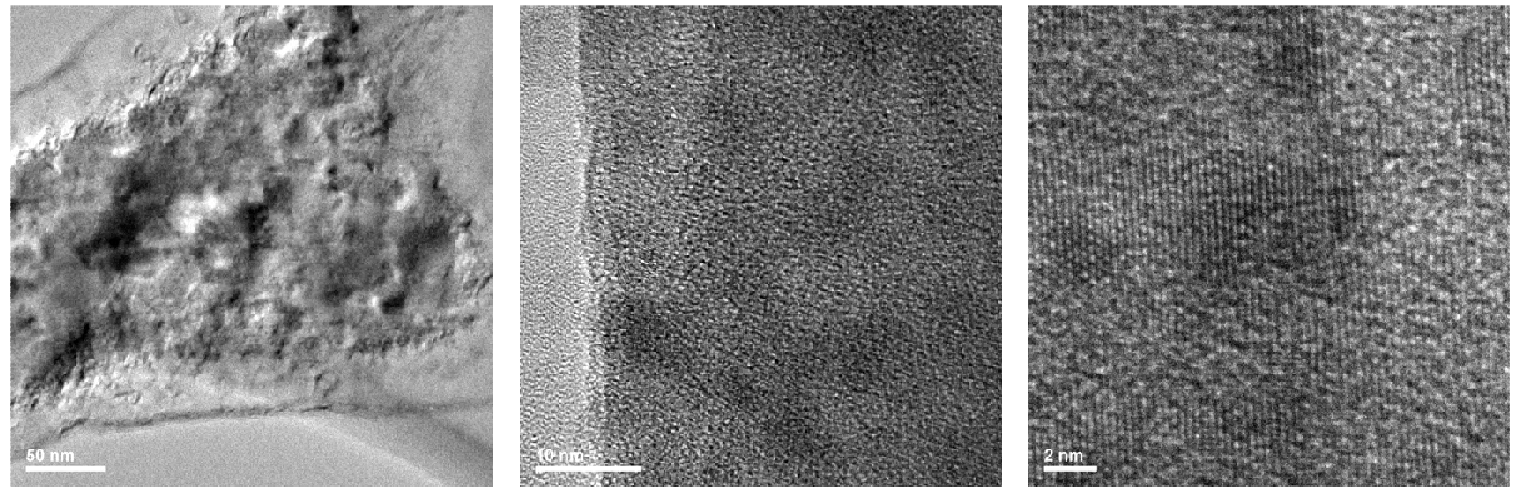

Figure S6. TEM images of $\mathrm{G} 5 \mathrm{C} 12_{\text {anch }}\left(\mathrm{Au}_{147}\right)$ pre extraction. Note the presence of dark spots approximately $\sim 2-3 \mathrm{~nm}$ in size. 